\title{
Prevalence of Malassezia sp isolation in body skin
}

Helena Schirmer*

UFCSPA

*Micology Laboratory - Federal University of Health Sciences of Porto Alegre (UFCSPA) - Street Sarmento Leite, 245/205 - 90050-170.

E-mail: helenasc@ufcspa.edu.br

\section{OBJECTIVE}

Pityriasis versicolor is a very common superficial mycoses caused by lipophilic yeasts of the genus Malassezia sp. This infection has been reported worldwide but is predominant in tropical climates and frequently in young adults. There are two clinical variaties: hypochromic or hyperpigmented macules, that usually develop in upper members as face, trunk, neck, and arms. In the last years, we have been isolated the yeasts in sites of the body with low density of sebaceous glands. So, the presented study was performed to asses the distribution of Malassezia sp in skin infection from 2014 to 2017.

\section{METHODS}

It was analyzed samples collected from January 2014 to December 2017, in a private Clinical Analysis Laboratory in the South of Brazil. The samples were collected from patients clinically suspected of skin infections and sent to the mycology sector. To Malassezia research, was prepared to direct exam with $\mathrm{KOH} 20 \%$ with Parker Quink Permanent ink, and confirm when the analyzer saw short hiphae and blastoconidia (Figure 1).

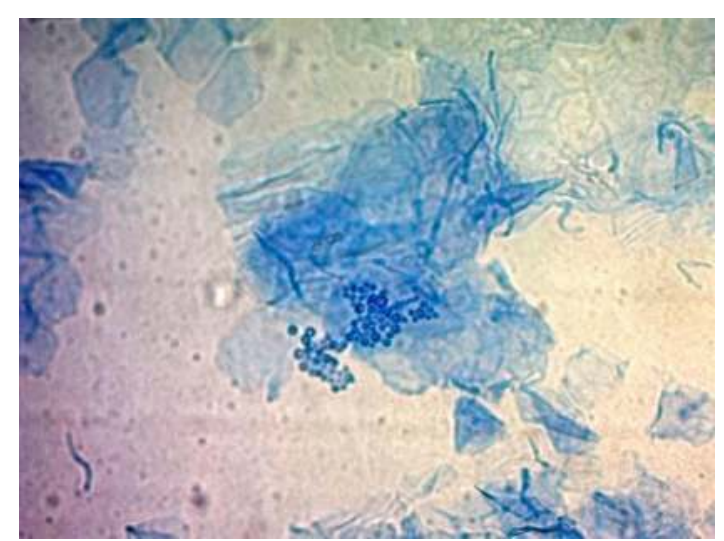

Figure 1. direct exam with KOH 20\% + Parker Quink Prmanent ink

\section{RESULTS}

It were obtained samples from 4958 patients, where sometimes one patient had more than one site to collect. There were 214 positive samples to Malassezia sp., being 121 (56,6\%) from young female. The age ranged from 1 to 84 years, being most positive samples collected from the patients with 20 years old or more, both in female and male. Fourteen patients had positive to Malassezia in two or more sites of the body. The prevalence of Malassezia sp identification did not range so much between the years, varying 3,5 to $4,7 \%$ samples per year. The most of positive samples were collected to upper members, being back $(25,70 \%)$ and thorax $(12,15 \%)$ more prevalent. Besides of this, it was identified yeast in other sites rich in sebaceous gland and, it was curious, some positive samples harvested in lower members as thigh $(2,8 \%)$ and groin $(3,74 \%)$.

\section{CONCLUSION}

The present work provided the ocurrence of ptiriasys versicolor in young adult population from a tropical country. Besides being more prevalent in young adults, it is important to attend that can attack newborn and elderly people. As, it is important to highlight to health professional the ocurrence of yeast in no common sites of body. This ocurrence propably is related to the increase and use of oil body lotion that predisposes the yeast growth in areas with low sebaceous gland. 